\title{
The Influence of Demographic, Environmental and Physical Factors on Functional Independence Post Stroke
}

\begin{abstract}
Purpose: The magnitude of disability observed in stroke survivors is believed to be dependent in part, on the severity of neurological deficits incurred. As important but less well understood, is the contribution of demographic, physical and environmental factors. The objective of this study was to establish what demographic, environmental and physical factors influence functional independence post stroke.

Method: Convenience sampling was used in the selection of subjects from four stroke outpatient public health facilities in the Gauteng Province of South Africa. The data were collected using a structured questionnaire. The analytical tools used included descriptive statistics to measure percentages and cross tabulations to measure the level of

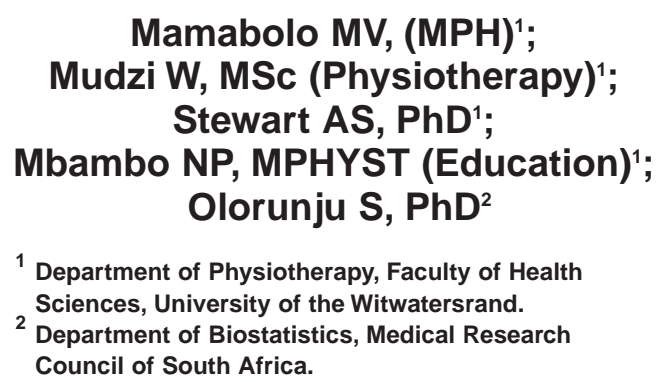

1 Department of Physiotherapy, Faculty of Health Sciences, University of the Witwatersrand.

2 Department of Biostatistics, Medical Research Council of South Africa. associations between functional independence and some of the demographic factors. The Barthel Index was computed to establish the degree of functional independence. Finally the influence of factors on functional independence was investigated using bivariate logistic regressions.

Results: The results showed that younger patients (18 - 34 yrs) may have a higher likelihood of functional independence compared to older patients at the time of discharge from hospital $(18-34$ years: Odds Ratio $=1)$. Patients without helpers were more likely to be functionally independent than those with a helper $(p=0.03)$. Involvement in household activities $(p=0.01)$, participation in community activities $(p=0.02)$ and bowel and bladder continence ( $p=0.003$ and $p=0.04$ ) improved the likelihood of functional independence.

Conclusion and implications: Factors that influence functional independence post stroke are: age, bowel and bladder continence, the presence of a caregiver, participation in household and community activities. It is also of value to encourage patients to participate in household and community activities post stroke as well as being less dependent on helpers in an effort to attain functional independence post stroke.
\end{abstract}

KEYWORDS: STROKE, FUNCTIONAL INDEPENDENCE.

\section{INTRODUCTION}

There has been an improvement in health delivery since the 1950's but despite these improvements, stroke remains a major source of functional disabilities (Ashburn 1999). About 50\% of all patients who have had a stroke have some residual physical disability (Ashburn 1999) and about 66\% of stroke survivors in South Africa require help with at least one activity of daily living (Connor et al 2004).

Following a stroke, many factors influence the degree of functional independence. Patients with the same diagnosis end up with different functional outcomes which are dependent on the patient treatment regimen and patient characteristics (Tilling et al 2001). Being older, presence of co-morbid diseases, continence (Barer 1989) and socio-demographic factors have been found to have an influence on the process of disability (Kelly-Hayes et al 2003). More women than men experience stroke and are more disabled at six months post stroke (Kelly-Hayes et al 2003).

The amount of social support a patient gets after having a stroke is positively associated with the extent of the functional status (Glass et al 1993) with socially isolated stroke patients being at risk of poor function (Glass et al 1993). Patients who have had a stroke generally function better in activities of daily living than they do in social activities and interactions (Schmidt et al 1986). Living with a spouse following a stroke cannot be considered a negative or positive predictor of functional independence without considering the pre-morbid role of the spouse or patient within the family unit (Schepers et al 2005).

Stroke subtype is one of the characteristics that can be identified and compared with functional ability. There

\section{Correspondence to:}

Veronica Mamabolo

Faculty of Health Sciences

University of the Witwatersrand

7 York Road,

Parktown 2193

South Africa

Tel: (011) 7173702

Fax: (011) 7173719

Email:

Mokgobadibe.Mamabolo@wits.ac.za 
is evidence of better functional progress in stroke survivors with haemorrhagic stroke when compared to ischaemic stroke (Paolucci et al 2003). Although stroke subtype has been shown to have an influence on functional independence in some studies, these could not be established in this study because it is not common practice for patients to be diagnosed or classified according to stroke subtype in the referral hospitals for the clinics included in this study.

The aim of this study was to establish demographic, environmental and physical factors that influence functional independence of patients post stroke.

\section{METHOD}

Patients with stroke who were attending stroke classes at four public health facilities namely, Alexandra clinic in Alexandra, Chiawelo and Mofolo clinics, and Chris Hani Baragwanath hospital outpatient department, in SOWETO, South Africa were included in the study. Some of the patients were seen in their homes, as they were receiving home visits from the clinic physiotherapist, due to their inability to access transport to the health facility. The following patients were excluded from the study: patients who were dependent in activities of daily living (ADL) before the stroke and those who had more than one stroke as well as institutionalised or hospitalised patients.

\section{Sample size}

Sixty eight patients were included in the study. For every factor that is considered to have a possibility of influencing the results of a study, at least ten subjects are required (Nunnaly 1978). In this study six factors were identified from the literature as factors that could influence the results of the study. The identified factors were age, shoulder pain, duration in hospital, current financial role, presence of a helper and marital status.

\section{Ethical considerations}

Ethical clearance was granted by the University of the Witwatersrand committee for research on human subjects. Participation in the study was voluntary, and an information and consent letter were given to the patients to sign before their participation in the study.

\section{Procedure}

Information was collected using a structured questionnaire and a Barthel Index (BI), which was administered by the researcher and three trained research assistants. A detailed process of establishing the validity of the structured questionnaire was undertaken. Internal consistency was measured and yielded a Cronbach's reliability coefficient of 0.93 .

In cases where patients had receptive aphasia the patient had to be physically present to confirm their functional ability in order to minimise the effect of incorrect reporting by the caregiver.

The baseline BI was collected retrospectively to measure the patient's functional independence at discharge from the hospital or rehabilitation unit. The
BI score post discharge was also established during the interview.

The scoring of the BI was done using the United Kingdom system of scoring (Tilling et al 2001). A score of 12 (60\%) and above was regarded as representing functional independence, and that of less than 12 was regarded as showing dependence in activities of daily living (Granger et al 1979; Kelly-Hayes et al 2003).

\section{Data analyses}

Data were analysed using descriptive statistics. These included the use of frequency tables, percentages and cross tabulations to measure associations. The Barthel Index score was dichotomized in order to evaluate the effect of the factors enumerated above using logistic

Table 1: Demographic results $(n=68)$

\begin{tabular}{|c|c|}
\hline Source of subjects: & No. (\%) \\
\hline Alexandra clinic & 9 (13) \\
\hline Chiawelo clinic & $21(31)$ \\
\hline Mofolo clinic & $7 \quad(10)$ \\
\hline Chris Hani Baragwanath hospital & $31(46)$ \\
\hline Age distribution: & No. (\%) \\
\hline $18-34$ & 9 (13) \\
\hline $35-44$ & $11(16)$ \\
\hline $45-54$ & $20(29)$ \\
\hline $55-64$ & $17(25)$ \\
\hline $65-75$ & $11(16)$ \\
\hline Gender: & No. (\%) \\
\hline Male & $27(40)$ \\
\hline Female & $41(60)$ \\
\hline Marital status: & No. (\%) \\
\hline Single & $30 \quad(44)$ \\
\hline Divorcee & $4 \quad(6)$ \\
\hline Live-in-partner & $1 \quad(2)$ \\
\hline Married & $26 \quad(38)$ \\
\hline Widow & $7 \quad(10)$ \\
\hline Education level: & No. (\%) \\
\hline Grade 12 & $14 \quad(21)$ \\
\hline Up to grade 11 & $22 \quad(32)$ \\
\hline Up to grade 7 & $32(47)$ \\
\hline Stroke duration & No. (\%) \\
\hline 6 weeks - 6 months & $29(43 \%)$ \\
\hline$>6$ months - 12 months & $11(16 \%)$ \\
\hline$>12$ months - 24 months & $28(41 \%)$ \\
\hline
\end{tabular}


regressions. Odd ratios (OR) were computed with associated confidence interval.

\section{RESULTS AND DISCUSSION Study population:}

Demographic information of the study population is shown in Table 1.

Age is the only demographic factor that may have an influence on functional independence $(18$ - 34 years: OR $=1)$. (See Table 3) However this influence was only at discharge from hospital. This finding is similar to that of Jorgensen et al (1999) and Pohjahsvaara et al (1997) who established that younger patients have better functional outcomes at discharge from hospital and that older patients deteriorate significantly more in activities of daily living.

Functional independence more than six weeks post discharge was not dependent on the patient's age $(p=0.37)$. Thus the probability of regaining functional independence post discharge was similar for all age groups

(18 - 75 years). Differences between this finding and those in the literature could be due to this study's participants being somewhat younger than those in other studies (Kelly-Hayes et al 2003; Nakayama et al 1994; Pohjahsvaara et al 1997).

Incontinence is difficult to manage after discharge from hospital, and thus this affects the patient's functional independence and quality of life (Barer 1989; Brittain et al 2000; Lam et al 1992). Stroke patients who become continent have better functional outcome (Barer, 1989). Although these studies focused mainly on urinary incontinence, they all established that incontinence has a detrimental effect on functional outcome. Sixty two percent (43) of the patients in our study were bowel continent while $58 \%$ (40) were bladder continent. Bowel and bladder continence had a positive influence on functional independence $(p=0.003$ and $p=0.04)$. These findings are in line with what has been established in the literature.

Eighty percent of patients who did not have a caregiver had functional independence compared to $41 \%$ who had caregivers $(\mathrm{p}=0.02 ; \mathrm{OR}=23 ; \mathrm{CI}=$ 1.24 - 430.04). Living alone before having a stroke has been shown to increase the likelihood of improved functional independence post stroke (Stineman et al 1997). This is attributed to the fact that patients who live alone are more likely to be committed to their rehabilitation programme because they know that they are unlikely to receive assistance after discharge from the hospital or rehabilitation unit.

Some caregivers react by overprotecting and over caring for patients (Anderson et al 1995), and thus patients who have such caregivers are unlikely to achieve much functional independence because of the lack of opportunity to practice functional activities. In addition it seems that being married carries a risk for low quality of life, and that unmarried patients cope well with their impairments (Kauhanen et al 2000). In addition living with a spouse could be a negative predictor of social activity (Schepers et al 2005). Thus it is important to establish the role of the caregiver at all times.

Most patients (59\%) in this study had caregivers and did not achieve functional independence. It can thus be safely assumed that the caregivers of these patients were either not giving them an opportunity to practice, or did not know what they needed to do for the patient. The influence of availability of caregiver on functional independence shows that $80 \%$ of patients without caregivers were functionally independent compared to less than $65 \%$ in the other categories (i.e. those who have a caregiver during the day; day and night or night only). This further seems to confirm that not having a caregiver improves the chances of functional independence.

Participation in community activities increased the likelihood of being functionally independent (Table 2). Patients who participate in community activities either already have functional indepen-

Table 2: Influence of environmental factors on functional independence $(n=68)$

\begin{tabular}{|c|c|c|c|}
\hline \multirow[t]{2}{*}{ Factors } & \multicolumn{2}{|c|}{ Post discharge } & \multirow[b]{2}{*}{$p$ value } \\
\hline & $\mathrm{BI}<12$ & $\mathrm{BI}>12$ & \\
\hline Having a caregiver & & & 0.02 \\
\hline Yes (85\%) & 34 & 24 & \\
\hline No $(25 \%)$ & 2 & 8 & \\
\hline Time of availability of the caregiver & & $\begin{array}{l}\text { No. } \\
\text { (\% improved) }\end{array}$ & 0.04 \\
\hline No caregiver & 2 & $8(80 \%)$ & \\
\hline Day & 5 & $2(29 \%)$ & \\
\hline Night & 4 & $7(64 \%)$ & \\
\hline Day and night & 25 & $15(30 \%)$ & \\
\hline Participating in community activities & & & 0.02 \\
\hline Yes (n: $46=68 \%)$ & 1 & 45 & \\
\hline No (n: $22=32 \%)$ & 4 & 18 & \\
\hline Participating in household activities & & & 0.01 \\
\hline Yes (n: $36=53 \%)$ & 0 & 36 & \\
\hline No (n: 32 = 47\%) & 5 & 27 & \\
\hline
\end{tabular}


Table 3: Logistic regression and odds ratios results

\begin{tabular}{|l|l|l|l|l|c|}
\hline Score & Odds ratio & Std. Err. & $\mathbf{z}$ & $\mathbf{P}>|\mathbf{z}|$ & $\begin{array}{c}95 \% \\
\text { Confidence interval }\end{array}$ \\
\hline Age & & & & & \\
\hline Age 18-34 & 1.0000 & & & & \\
\hline Age 35 - 44 & 0.0074 & 0.0124 & -2.94 & 0.003 & $0.0002-0.1953$ \\
\hline Age 45 - 54 & 0.0148 & 0.0220 & -2.84 & 0.004 & $0.0008-0.2707$ \\
\hline Age 55 - 64 & 0.0165 & 0.0249 & -2.72 & 0.007 & $0.0008-0.3182$ \\
\hline Age 65 - 75 & 0.0055 & 0.0101 & -2.83 & 0.005 & $0.0001-0.2005$ \\
\hline Bowel function & 19.0512 & 19.2190 & 2.92 & 0.003 & $2.6376-37.6018$ \\
\hline Bladder function & 10 & 11.03026 & 2.09 & 0.04 & $1.1510-86.8755$ \\
\hline With helper & 1.0000 & & & & \\
\hline No helper & 23.1739 & 34.5353 & 2.11 & 0.035 & $1.2487-430.0473$ \\
\hline
\end{tabular}

dence, or they have appropriate help to integrate into the community (Schmidt et al 1986).

Participating in household activities was also found to increase the likelihood of being functionally independent (Table 2) as did Schepers et al (2005) who established that doing household work led to higher scores on functional independence post stroke.

\section{CONCLUSION}

Age may have an influence on functional independence during the initial stages of rehabilitation, but did not seem to have an influence on functional independence in the long term for stroke patients younger than 75 years of age. Having bowel and bladder continence and participating in household and community activities increased the chances of regaining functional independence. Having a caregiver decreased the chances of regaining functional independence.

\section{RECOMMENDATIONS}

Clinical recommendations: Therapists who provide rehabilitation services for patients who have had a stroke should involve the caregivers and give them information about the patient's condition and the role they (caregiver) are supposed to play in order to improve patients' functional independence post discharge. Caregivers should be informed about the importance of patients' participation in household and community activities. Older stroke patients (up to 75 years of age) should be given an opportunity to receive rehabilitation services.

\section{REFERENCES}

Ashburn A 1999 Physical recovery following stroke. Physiotherapy 83 (9): 480 - 490

Anderson CS, Linto J, Stewart-Wynne ED 1995 A Population-Based Assessment of the Impact and Burden of Caregiving for Long-term Stroke Survivors. Stroke 26: 843 - 849

Barer DH 1989 Continence after stroke: useful predictor or goal of therapy? Age Ageing 18 (3): 183 - 191

Boden-Albala B, Litwak E, Ekind MSV, Rundek T, Sacco RL 2005 Social isolation and outcomes post stroke.Neurology 64: 1888 - 1892

Brittain KR, Perry SI, Peet SM, Shaw C, Dallosso H, Assassa RP, Williams K, Jagger C, Potter JF, Castleden CM 2000 Prevalence and Impact of Urinary Symptoms Among Community-Dwelling Stroke Survivors. Stroke 31:886

Connor MD, Thorogood M, Casserly B, Dobson C, Warlow MD 2004 Prevalence of stroke survivors in rural South Africa: Results from the Southern Africa stroke prevention initiative (SASPI) Agincourt field site. Stroke 35: 627 632

Gass TA, Matchar DB, Belyea M, Feussner JR 1993 Impact of social support on outcome in first stroke. Stroke 24 (1): 64 - 70

Granger C, Dewis L, Peters N, Sherwood C, Barrett J 1979 Stroke rehabilitation: an analysis of repeated Barthel Index measures. Arch Phys Med Rehabil 60 (1): 14-17

Jorgensen HS, Reith J, Nakayama H, Kammersgaard LP, Raaschou HO, Osen TS, 1999 What determines good recovery in patients with the most severe strokes? The Copenhagen stroke study. Stroke 30: 2008 2012

Kauhanen M, Korpelainen J, Hiltunen $\mathrm{P}$, Nieminen P, Sotaniemi K, Myllyla V 2000 Domains and Determinants of Quality of Life After Stroke Caused by Brain Infarction. Arch Phys Med Rehabil 81: 1541 - 1546
Kelly-Hayes M, Beiser A, Kase CS, Scaramucci A, D'Agostino RB, Wolf PA 2003 The Influence of Gender and Age on Disability following Ischemic Stroke: the Framingham study. Journal of Stroke and Cerebrovascular Diseases 12: 119 - 126

Lam GW, Foldspang A, Eving LB, Mommsen S 1992 Social context, social abstention, and problem recognition correlated with adult female urinary incontinence. Dan Med Bull 39 (6): 565 - 570

Nakayama H, Jorgensen HS, Raaschou HO, Osen TS 1994 The influence of age on stroke outcome. The Copenhagen Stroke Study. Stroke 25 (4): 808 - 813

Nunnaly JC 1978 Psychometric theory, 2nd edn.pp 230 - 245. McGraw-Hill, New York

Paolucci S, Antonucci G, Gasso MG, Bragoni M, Coiro P, De Angelis D, Fusco R, Morelli D, Venturiero V, Troisi E, Pratesi L 2003 Functional Outcome of Ischemic and Haemorrhagic Stroke Patients After Inpatient Rehabilitation: A matched comparison. Stroke 34: 2861

Pohjahsvaara T, Erkinjuntti T, Vataja R, Kaste M 1997 Comparison of stroke Features and Disability in Daily Life in Patients With Ischaemic Stroke Aged 55 to 70 and 71 to 85 Years. Stroke 28: 729 - 735

Schepers V, Visser-Meily A, Ketelaar M, Lindeman E2005 Prediction of Social Activity 1 Year Poststroke. Arch Phys Med Rehabil 86: 1472 - 1476

Schmidt S, Herman L, Koenig P, Leuze P, Monahan M 1986 Status of stroke patients: a community assessment. Arch Phys Med Rehabil 67 (2): 99 - 102

Stineman M, Maislin G, Fiedler RC, Granger CV 1997 A Prediction Model for Functional Recovery in Stroke. Stroke 28: 550 - 556

Tilling K, Sterne J, Rudd A, Glass T, Wityk R, Wolfe C 2001 A new method for predicting recovery after stroke. Stroke 32: 2867 - 2873 